\section{IN THE NEWS}

\section{Cancer clusters}

Lawsuits by two former IBM employees went before a jury in late October, alleging that both were routinely exposed to carcinogenic chemicals at the company's hard-drive facility in San José, California. The suit claims that health records show that IBM physicians knew about the higherthan-average incidence of cancer among employees.

"The case is the first of more than 200 similar worker lawsuits against IBM in various states to reach the trial stage" (New York Times, 13 October 2003).

During the production of many electronic components such as hard drives and semiconductors, workers in 'clean rooms' are continually exposed to a broad array of carcinogenic chemicals. "According to court files, hundreds of IBM workers developed relatively rare forms of cancer in their 30s, 40s and 50s" (ABC News, 25 September 2003)

Central to the plaintiffs' case is a database kept by IBM known as the

'Corporate Mortality File' a record of the cause of death for more than 30,000 full-time employees over a 30-year period. A prominent epidemiologist has analysed the records and found that IBM employees have a shorter life expectancy than the general population, and that a cancer trend could have been detected as early as the 1970s. "IBM calls the analysis 'junk science', and has said that the Corporate Mortality File is an incomplete and error-prone employee benefits record" (Reuters, 5 October 2003)

"The case could have ramifications throughout the high-technology sector, where many of the same chemicals were in widespread use in the 1970s and 1980s" (New York Times, 13 October 2003)

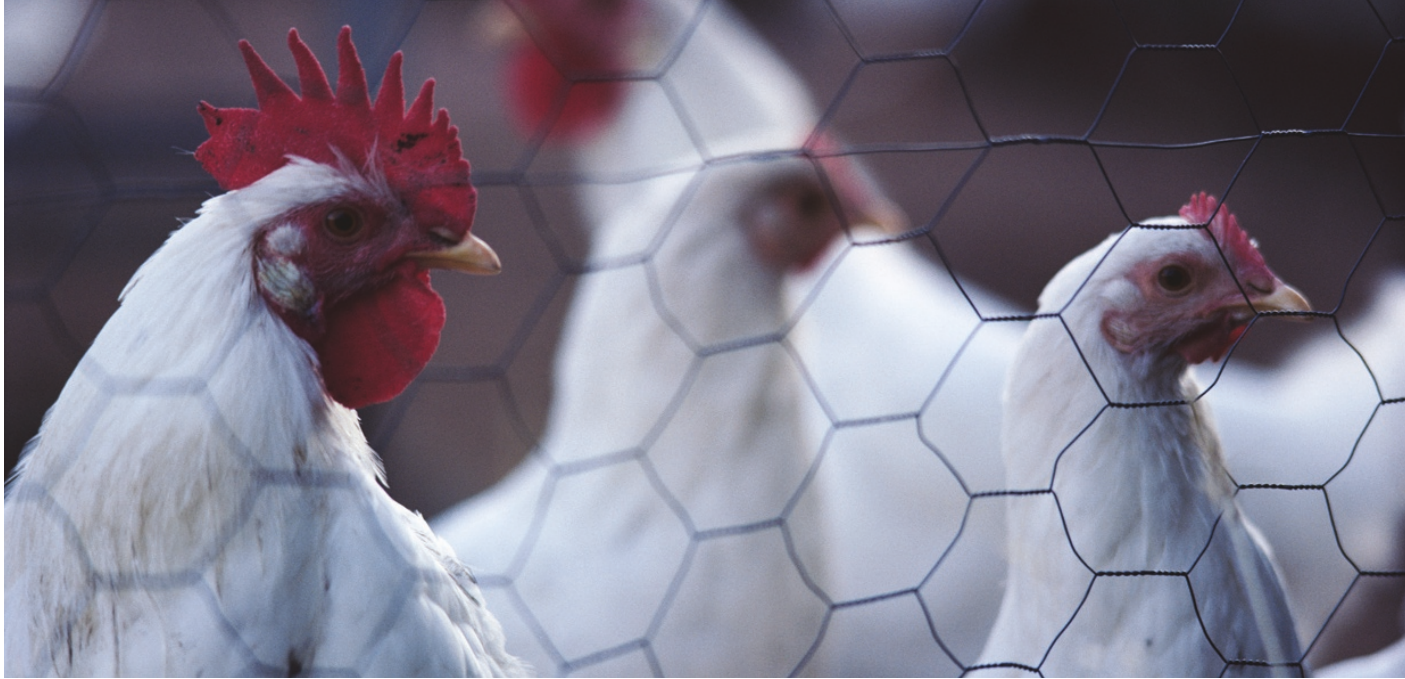

ANGIOGENESIS

\title{
Artificial systems
}

Can controlled systems ever truly simulate natural environments? Do animals on a farm behave the same way as they would in their natural habitat? Probably not. So, perhaps it should come as no surprise that tumour xenografts and spontaneously arising tumours respond in different ways to angiogenic stress, as Marianna Ruzinova et al. and Hashmat Sikder et al. both report in the October issue of Cancer Cell. Id proteins are negative regulators of basic helix-loop-helix transcription factors and are essential for angiogenesis and growth of tumour xenografts; however, the role of Id proteins in spontaneous tumours was not known until now.

Ruzinova et al. studied spontaneous tumour development in $\mathrm{Pten}^{+/-}$mice and observed that loss of Id genes does not curtail the rate of growth of hyperplastic lymphoid lesions or uterine carcinomas. Sikder et al. used carcinogenic chemicals to induce spontaneous tumour growth in $I d 1^{-/-}$mice and these mice actually had a higher incidence of skin tumours than wild-type controls.

So, loss of Id did not inhibit the growth rate of spontaneous tumours, but what was the effect on the neovasculature and tumour histology? Ruzinova et al. observed that both $I d 1$ and $I d 3$ are overexpressed in the vasculature of the lymph and uterine tumours that develop in $\mathrm{Pten}^{+/}$mice. These tumours become necrotic and undergo haemorrhage in an Id-mutant background. Pheochromocytomas, which do not normally overexpress Id in their vasculature, were not affected by reduced $I d$ dosage.

Previous studies in xenografts showed that reduction of Id dosage severely stunted neovascularization, but in the more physiologically relevant $\mathrm{Pten}^{+/-}$model, tumour vasculature was impaired in a different way - anastomosing networks of enlarged, irregularly shaped blood vessels, Hif- $1 \alpha$ overexpression and increased vascular permeability were all observed. By contrast, Sikder et al. did not observe defects in angiogenesis in their $I d^{-/-}$mouse model - vessel density and calibre were similar to that of $I d^{+/+}$mice, although whether these tumour vessels normally express Id genes was not established.
Xenograft vascularization relies on bonemarrow-derived circulating endothelial precursors (BM-CEPs). Ruzinova et al. showed that in $\mathrm{Pten}^{+/}$ mice BM-CEPs contribute to the vasculature of uterine carcinomas and restore functionality, but do not contribute to the neovessels of lymphoid hyperplasias, demonstrating that dependence on the requirement for these precursors varies with tumour type.

But what are the downstream targets of Id? Ruzinova and colleagues compared gene-expression profiles of endothelial cells from tumours that developed in the $\mathrm{Pten}^{+/-} \mathrm{Id} \mathrm{I}^{+/+}$mice and $\mathrm{Pten}^{+/-} \mathrm{Id} \mathrm{I}^{-/-}$ mice and found that $I d 1$ controls expression of several angiogenesis-associated factors, including $\alpha 6$ and $\beta 4$ integrins, matrix metalloproteinase 2 and fibroblast growth factor receptor 1. Expression of thrombospondin-1, previously found to be upregulated in $I d 1^{-1-}$ mouse embryonic fibroblasts, was not upregulated in the vasculature of $I d 1^{-/-}$ spontaneous tumours. Sikder and colleagues showed that loss of $I d 1$ caused loss of expression of the chemokine receptor Cxcr4 by a T-cell subgroup that is involved in tumour immunosurveillance. This prevented homing of these cells to the skin, leaving skin tumour development unchecked.

These data challenge the long-held view that tumours cannot grow beyond a limited size under severe angiogenic stress, and highlight the need to use mouse models of spontaneous tumours in further studies.

Ezzie Hutchinson

6) References and links

Original Research PAPER Ruzinova, M. B. et al. Effect of

angiogenesis inhibition by Id loss and the contribution of bone-marrowderived endothelial cells in spontaneous murine tumors. Cancer Cell 4 277-289 (2003) | Sikder, H. et al. Disruption of Id1 reveals major differences in angiogenesis between transplanted and autochthonous tumors. Cancer Cell 4, 291-299 (2003)

WEB SITES

Robert Benezra's lab: http://www.mskcc.org/mskcc/html/10469.cfm Vivek Mittal's lab: http://www.cshl.org/public/SCIENCE/mittal.htm Rhoda M. Alani's lab:

http://www.hopkinsmedicine.org/pharmacology/pages/faculty/alani.html 